\title{
Ancient Impact and Aqueous Processes at Endeavour Crater, Mars
}

\section{Citation}

Squyres, S. W., R. E. Arvidson, J. F. Bell III, F. Calef III, B. C. Clark, B. A. Cohen, L. A. Crumpler, et al. 2012. Ancient impact and aqueous processes at Endeavour crater, Mars. Science 336(6081): 570-576.

\section{Published Version}

doi:10.1126/science. 1220476

\section{Permanent link}

http://nrs.harvard.edu/urn-3:HUL.InstRepos:10735581

\section{Terms of Use}

This article was downloaded from Harvard University's DASH repository, and is made available under the terms and conditions applicable to Other Posted Material, as set forth at http:// nrs.harvard.edu/urn-3:HUL.InstRepos:dash.current.terms-of-use\#LAA

\section{Share Your Story}

The Harvard community has made this article openly available.

Please share how this access benefits you. Submit a story.

\section{Accessibility}




\section{Ancient Impact and Aqueous Processes at Endeavour Crater, Mars}

S.W. Squyres ${ }^{1 *}$, R.E. Arvidson ${ }^{2}$, J.F. Bell $\mathrm{III}^{3}$, F. Calef $\mathrm{III}^{4}$, B.C. Clark ${ }^{5}$, B.A. Cohen ${ }^{6}$, L.A. Crumpler $^{7}$, P.A. de Souza Jr. ${ }^{8}$, W.H. Farrand ${ }^{5}$, R. Gellert ${ }^{9}$, J. Grant ${ }^{10}$, K.E. Herkenhoff ${ }^{11}$, J.A. Hurowitz $^{4}$, J.R. Johnson ${ }^{12}$, B.L. Jolliff ${ }^{2}$, A.H. Knoll ${ }^{13}$, R. Li $^{14}$, S.M. McLennan ${ }^{15}$, D.W. Ming ${ }^{16}$, D.W. Mittlefehldt ${ }^{16}$, T.J. Parker ${ }^{4}$, G. Paulsen ${ }^{17}$, M.S. Rice ${ }^{1}$, S.W. Ruff ${ }^{3}$, C. Schröder ${ }^{18}$, A.S. $\mathrm{Yen}^{4}$, K. Zacny ${ }^{17}$

${ }^{1}$ Dept. of Astronomy, Space Sciences Bldg., Cornell University, Ithaca, NY 14853, USA

${ }^{2}$ Dept. of Earth and Planetary Sciences, Washington University, St. Louis, MO 63031, USA

${ }^{3}$ School of Earth and Space Exploration, Arizona State University, Tempe, AZ 85287, USA

${ }_{5}^{4}$ Jet Propulsion Laboratory, California Institute of Technology, Pasadena, CA 91109, USA

${ }^{5}$ Space Science Institute, Boulder, CO 80301, USA

${ }^{6}$ NASA Marshall Space Flight Center, Huntsville, AL 35812, USA

${ }^{7}$ New Mexico Museum of Natural History \& Science, Albuquerque, NM, 87104, USA

${ }^{8}$ Human Interface Technology Laboratory, University of Tasmania, Launceston, TAS 7250, Australia

${ }^{9}$ Department of Physics, University of Guelph, Guelph, ON, N1G 2W1, Canada

${ }^{10}$ Center for Earth and Planetary Studies, Smithsonian Institution, Washington, D.C. 20560, USA

${ }^{11}$ U.S. Geological Survey, Astrogeology Science Center, Flagstaff, AZ 86001, USA

${ }^{12}$ Applied Physics Laboratory, Johns Hopkins University, Laurel, MD 20723, USA

${ }^{13}$ Botanical Museum, Harvard University, Cambridge MA 02138, USA

${ }^{14}$ Dept. of Civil \& Env. Eng. \& Geodetic Science, Ohio State University, Columbus, OH 43210, USA

${ }^{15}$ Dept. of Geosciences, State University of New York, Stony Brook, NY 11794, USA

${ }^{16}$ ARES, NASA Johnson Space Center, Houston, TX 77058, USA

${ }^{17}$ Honeybee Robotics \& Spacecraft Mechanisms Corporation, Pasadena, CA 91103, USA

${ }^{18}$ Universität Bayreuth und Eberhard Karls Universität, 72076 Tübingen, Germany

*To whom correspondence should be addressed. Email: squyres@astro.cornell.edu 


\begin{abstract}
The rover Opportunity has investigated the rim of Endeavour Crater, a large ancient impact crater on Mars. Basaltic breccias produced by the impact form the rim deposits, with stratigraphy similar to that observed at similar-sized craters on Earth. Highly localized Zn enrichments in some breccia materials suggest hydrothermal alteration of rim deposits. Gypsum-rich veins cut sedimentary rocks adjacent to the crater rim. The gypsum was precipitated from low-temperature aqueous fluids flowing upward from the ancient materials of the rim, leading temporarily to potentially habitable conditions and providing some of the waters involved in formation of the ubiquitous sulfate-rich sandstones of the Meridiani region.
\end{abstract}


After more than 7 years of operations and $33 \mathrm{~km}$ of traversing, the Mars Exploration Rover Opportunity has reached Endeavour Crater. Endeavour is $\sim 22 \mathrm{~km}$ in diameter and formed in Noachian (1) materials that predate the sulfate-rich sedimentary rocks explored by Opportunity for most of its mission $(2,3)$. Endeavour was chosen as a target because the rocks there record an ancient epoch in martian history, and because orbital infrared data show that phyllosilicate minerals are present in portions of the crater rim (4).

Opportunity arrived at Endeavour Crater on Sol 2681 (5) of its mission, at a low-lying segment of the rim, $\sim 700 \mathrm{~m}$ in length, named Cape York (Fig. 1). Shoemaker Ridge (6) forms the spine of Cape York, and is the type locality for the Noachian materials of the rim, which we call the Shoemaker formation. Opportunity first arrived at Spirit Point, the southern tip of Cape York, and then traversed northward $851 \mathrm{~m}$ before stopping at Greeley Haven (7) at the northern end of Cape York to spend the martian winter.

Instruments of Opportunity's Athena payload $(8,9)$ were used to investigate materials within the Shoemaker formation, including the bedrock outcrop Chester Lake (Fig. 2) near the southern end of Shoemaker Ridge, and several bedrock targets near Greeley Haven at the northern end. Although separated by more than half a kilometer, these outcrops are similar in physical appearance and elemental chemistry; we interpret them to represent the dominant surface rock type of Cape York.

Chester Lake and all the rocks near Greeley Haven have similar textures. They are brecciated, with dark, relatively smooth angular clasts up to $\sim 10 \mathrm{~cm}$ in size embedded in a brighter, fractured, fine-grained matrix. Some outcrops, notably Chester Lake, show fine-scale lineations in the matrix and alignment of some clasts (Fig. 2). Pancam spectra of the matrix 
exhibit a gradual decrease in reflectance toward $1000 \mathrm{~nm}$. The clasts can show specular reflections, have a relatively deep absorption at $934 \mathrm{~nm}$, and a shallower $535 \mathrm{~nm}$ absorption than the matrix materials, consistent with relatively unoxidized basaltic material containing low-Ca pyroxene.

The matrix of Chester Lake is easily abraded. Using the rover's Rock Abrasion Tool (RAT), a portion of Chester Lake dominated by matrix was abraded to a depth of $\sim 2.5 \mathrm{~mm}$. Resistance to abrasion is quantified using specific grind energy, the energy required to abrade away a unit volume of rock. The specific grind energy for Chester Lake was $\sim 1.5 \mathrm{~J} \mathrm{~mm}^{-3}$. Representative values for weak terrestrial materials are $0.7-0.9 \mathrm{~J} \mathrm{~mm}^{-3}$ for chalk and 4.8-5.3 J $\mathrm{mm}^{-3}$ for gypsum (10). Chester Lake is substantially weaker than all but one of the 14 diverse rocks abraded by Spirit at Gusev Crater (11), but comparable to the sulfate-rich sandstones at Opportunity's landing site (12).

At Chester Lake we used the Alpha Particle X-Ray Spectrometer (APXS) to measure the elemental composition of both the matrix (after abrasion by the RAT) and one of the clasts. Measurements were also made of three targets near Greeley Haven: Transvaal and Boesmanskop (both matrix) and Komati (a clast). All are similar to one another in composition, and all are similar to the basaltic sand typical of the Meridiani region (Table 1). The major elements ( $\mathrm{Na}$, $\mathrm{Mg}, \mathrm{Al}, \mathrm{Si}, \mathrm{Ca}$ and $\mathrm{Fe}$ ) are mostly within $10 \mathrm{wt} \%$, and all but a few are within $20 \mathrm{wt} \%$, of the basaltic sand composition.

$\mathrm{Fe} / \mathrm{Mn}$ ratios of the matrix range from 40 to 44 , and "Mg numbers" (molar $\left.100 \times \mathrm{Mg} /\left(\mathrm{Mg}+\mathrm{Fe}_{\mathrm{T}}{ }^{2+}\right)\right)$ of all samples range from 41 to 48 . These are within the ranges of basaltic meteorites from Mars (36-45 and 24-68, respectively (Fig. S1)) and indicate that any alteration of 
the protolith of these rocks did not substantially mobilize $\mathrm{Mg}, \mathrm{Mn}$, or Fe. P contents are higher than basaltic sand, and $\mathrm{Cr}$ contents are lower. However, these minor elements follow trends of martian basaltic and lherzolitic meteorites (Fig. S1), suggesting that igneous fractionation established the major and minor element concentrations.

We interpret all of these rocks to be breccias formed during the Endeavour impact. The compositional similarity to Meridiani basaltic sand is consistent with the view that both materials broadly reflect the composition of the surficial crust in this region.

While we cannot assess the degree of shock metamorphism of the clasts or the presence of glass in the matrix, we note that the texture of these rocks is similar to that typical of suevite breccias (13) common in impact settings on Earth and the Moon. For terrestrial suevites, particle shape fabrics have been reported oriented radial to the impact point, and have consequently been related to the emplacement flow (14). The linear fabric in Chester Lake is oriented within $\sim 5^{\circ}$ of radial to the center of Endeavour, although we cannot rule out the possibility that this texture is erosional rather than primary.

Near the southern end of Shoemaker Ridge, Opportunity encountered Odyssey crater (Fig. 1). Odyssey is elliptical, $\sim 23 \times 19 \mathrm{~m}$, with its major axis oriented orthogonal to a field of ejecta blocks that extends to the southeast. The ejecta block Tisdale was investigated in detail. Tisdale differs texturally and compositionally from Chester Lake and Greeley Haven rocks. Because it was excavated from Odyssey crater, Tisdale may represent a deeper unit within the Shoemaker formation. Tisdale and other Odyssey ejecta blocks are breccias, with poorly sorted, closely packed angular to rounded clasts up to several $\mathrm{cm}$ in size (Fig. 3). Tisdale lacks the extensive fine-grained matrix of Chester Lake and other rocks, and contains lithic fragments over 
a wide range of grain sizes.

The clasts in Tisdale exhibit spectral variability beyond that expected from discontinuous dust coatings, including positive and negative near-infrared spectral slopes and some $903 \mathrm{~nm}$ absorptions. Small, localized spots in Tisdale and nearby rocks exhibit $860 \mathrm{~nm}$ and $535 \mathrm{~nm}$ absorptions possibly consistent with a ferric phase and/or minor hydrated $\mathrm{Mg} / \mathrm{Fe}$ silicates. Based on its textural and color properties, we interpret Tisdale as a lithic breccia that is possibly polymict.

APXS measurements of Tisdale were made at three locations on a relatively dust-free vertical face (Table 1). The results are similar to Chester Lake and the Greeley Haven outcrops, but $\mathrm{Mg}$ is lower and $\mathrm{P}$ and the trace elements $\mathrm{Ni}, \mathrm{Zn}$, and $\mathrm{Br}$ are higher and quite variable. One location has the highest $\mathrm{Zn}$ content $\left(\sim 6300 \mu \mathrm{g} \mathrm{g}^{-1}\right)$ of all analyses from Mars. The $\mathrm{Zn}$ and Ni elemental trends are similar to trends in hydrothermally altered rocks around Home Plate in Gusev crater (15). Variable P enrichment may result from metasomatism of silicate materials by P-rich hydrothermal solutions (16) or acidic solutions dissolving P from source rocks and reprecipitating it (17). It is unlikely, however, that the high $\mathrm{P}$ simply reflects a different igneous composition than the Chester Lake target material, as the Tisdale targets do not follow typical igneous fractionation trends, such as that defined by martian meteorites (Fig. S1c).

It is instructive to compare the rim deposits of Endeavour Crater to those of the comparably sized Ries impact structure in Germany (18). At the Ries, thin deposits of surficial suevite (19), often just a few m thick, overlie the Bunte Breccia that dominates the impactites of the rim (20). The Bunte Breccia is a poorly sorted polymict lithic breccia. It represents the continuous ballistic ejecta deposit, and is derived primarily from the uppermost lithologies of the target (21). Rounded clasts are common. The surficial suevite that overlies it was deposited late 
in the impact process, either via fallout from a gaseous ejecta plume (22) or as a surface-hugging flow (23). We suggest that a similar relationship may hold at Endeavour, with Tisdale representing the main breccia unit of the rim, and Chester Lake and the rocks near Greeley Haven emplaced later in the impact flow.

Tisdale's Zn abundances correlate with both $\mathrm{S}$ and $\mathrm{P}$, suggesting that Zn sulfides, sulfates, and/or phosphates could be present. High-Zn materials on Earth are common in settings like volcanogenic massive sulfide deposits, where hydrothermal circulation has mobilized $\mathrm{Zn}$ and caused precipitation of Zn sulfides and development of associated alteration products (24). The heating caused by an impact the size of Endeavour is sufficient to cause hydrothermal circulation if water is present (25). We suggest that the $\mathrm{Zn}$ enrichment in Tisdale could have resulted from such activity. Enrichments of trace metal mineralization by hydrothermal fluids will naturally be localized where fluids readily flow, including fractures, zones with increased permeability, and other void spaces. Highly heterogeneous distribution of secondary mineralization is therefore expected.

When normalized to the average composition of the sulfate-rich sandstones comprising the Burns formation of the Meridiani plains (2,3), all rocks of the Shoemaker formation show fractionations among the major elements, e.g. high $\mathrm{Na} / \mathrm{Mg}$ and $\mathrm{Al} / \mathrm{Mg}$ (Fig. S2). Either the Shoemaker formation is not representative of the feedstock for the sulfate-rich grains of the Burns formation, or the alteration process that formed those grains resulted in major compositional changes.

The composition of Shoemaker formation rocks is also not a good match to either Bounce Rock (26) or Marquette Island (27), two basaltic rocks encountered earlier in Opportunity’s 
mission that lie atop Burns formation sandstones. These must be ejecta blocks from distant craters that postdate Endeavour, sampling different crustal materials.

Cape York is encircled by a gently outward-sloping topographic bench $\sim 6 \mathrm{~m}$ wide on the west and up to $20 \mathrm{~m}$ wide on the east (Fig. 1). The outer part of the bench on the western side exposes bright thinly bedded sandstones with bedding that dips shallowly toward the plains. These sandstones lie directly above darker granular sedimentary rocks that form the inner portion of the bench. This stratigraphic relationship is interpreted as the unconformable onlapping contact of the Burns formation onto older sedimentary materials shed from the Shoemaker formation. The inner bench materials, in turn, overlie the Noachian breccias that form the lower slopes of Cape York.

Bench materials are cut in many places by bright linear veins. Veins are prominent in the poorly exposed dark sedimentary materials of the inner bench, but occur within the bright outcrops of the basal Burns sandstone as well. Measurements of 37 veins yield a mean width of 2 $\mathrm{cm}$ and a mean exposed length of $33 \mathrm{~cm}$. Most vein orientations lie subparallel to the margins of Cape York.

Opportunity investigated one of these veins, named Homestake (Fig. 4), near the northern end of Cape York. Homestake forms a discontinuous, flat-topped ridge 1-1.5 cm wide and $\sim 50$ $\mathrm{cm}$ long. It stands up to $\sim 1 \mathrm{~cm}$ above the surrounding bedrock, suggesting that it is more erosionresistant than the material into which it was emplaced. MI images reveal a fine linear texture perpendicular to the trend of the vein.

Three separate APXS analyses were conducted on Homestake. All were similar (Table 1), with high abundances of $\mathrm{SO}_{3}$ and $\mathrm{CaO} . \mathrm{The}_{3} / \mathrm{CaO}$ ratio is within a few percent of 
stoichiometry for $\mathrm{CaSO}_{4}$, with a possible slight excess of sulfate. Other cations such as $\mathrm{Mg}, \mathrm{K}$, $\mathrm{Al}$ and $\mathrm{Fe}$ do not show positive correlation with $\mathrm{S}$, but $\mathrm{Na}$ does, so a small amount of Na sulfate could be present.

The non-salt portion of the APXS measurement of Homestake is dominated by Si and Al, which are highly correlated with each other $\left(\mathrm{R}^{2}=0.89\right)$, and anti-correlated with $\mathrm{S}\left(\mathrm{R}^{2}=0.97\right.$ to 0.99). MI images (Fig. 4b) show, however, that significant contaminants must be present in this measurement. Homestake does not fill the $\sim 3.8 \mathrm{~cm}$ circular field of view of the APXS, so contamination by background material (mostly dark sand in the MI images) must be present. MI images of Homestake show a mottled upper surface, also suggesting surface contamination.

Modeling the composition of Homestake as a three-component mixture of calcium sulfate, typical Meridiani basaltic sand, and typical martian dust, and accounting for the energy dependence of the signal from a thin dust layer, we find that the composition in Table 1 is matched by a mixture of $43 \% \mathrm{CaSO}_{4}, 29 \%$ sand, and $28 \%$ dust $4 \mu \mathrm{m}$ thick (28). Because the MI images are consistent with these amounts of background sand and surface dust contamination, we conclude that the vein material itself is predominantly $\mathrm{CaSO}_{4}$, with perhaps minor $\mathrm{Na}_{2} \mathrm{SO}_{4}$, phosphate, and a Cl-containing salt.

Calcium sulfates can have a range of hydration states. Pancam's longest wavelength filter $(1009 \pm 19 \mathrm{~nm})$ provides the ability to detect remotely and map spatially certain hydrated minerals, based on the presence of the $2 v_{1}+v_{3} \mathrm{H}_{2} \mathrm{O}$ combination absorption band and/or the $3 v_{\mathrm{OH}}$ overtone absorption band centered near $\sim 1000 \mathrm{~nm}$ in many minerals containing bound $\mathrm{H}_{2} \mathrm{O}$ and/or $\mathrm{OH}^{-}(29,30)$. 
Figure 5a shows that hydrated mineral signatures (characterized four total spectral parameters (30), including steeply negative slopes from 934 to $1009 \mathrm{~nm}$ ) are detected in Homestake. These spectral features occur in three separate unsaturated Pancam observations acquired at different viewing geometries and incidence angles, convincing us that the signature is due to hydration in Homestake rather than any instrumental, calibration, or viewing geometry artifact (30). The magnitude of the hydration signature and the albedo increased after Opportunity drove over and exposed fresh crushed parts of Homestake, suggesting that the hydrated material is not a superficial coating or rind, but rather a component of the bulk volume of the vein material.

Laboratory reflectance spectra of calcium sulfates convolved to Pancam bandpasses (Fig. $5 b)$ suggest that the hydration signature is consistent with gypsum $\left(\mathrm{CaSO}_{4} \cdot 2 \mathrm{H}_{2} \mathrm{O}\right)$, but not anhydrite $\left(\mathrm{CaSO}_{4}\right)$ or bassanite $\left(\mathrm{CaSO}_{4} \bullet 0.5 \mathrm{H}_{2} \mathrm{O}\right)$. Anhydrite lacks a hydration band, and the weak bassanite hydration band is centered near $\sim 950 \mathrm{~nm}$, between Pancam's two longestwavelength band centers.

Gypsum veins have been reported in a variety of settings on Earth, where their formation is invariably attributed to precipitation from relatively low temperature (less than $\sim 60^{\circ} \mathrm{C}$ ) water in fractures (31-34). Vein growth is often antitaxial, with nucleation occurring at the vein-wall interface. Crystals precipitated in such settings are commonly fibrous, with long axes that track the opening trajectory of the fracture (34-36); fibers therefore form perpendicular to the vein axis when vein growth occurs in extension fractures. We suggest that the transverse lineations seen in MI images of Homestake are remnants of such a texture. The orientations of the veins themselves suggest that the rocks of the bench surrounding Cape York were subjected to horizontal tension perpendicular to the bench margins at the time of vein emplacement, perhaps 
related to sediment compaction, dewatering, and settling.

Homestake was emplaced in the darker inner unit of the bench surrounding Cape York. The rock of this unit is platy in appearance, with mm-scale layering that is poorly exposed but shows locally varying strikes and dips. Its elemental composition, measured at a location named Deadwood (Table 1), is similar to Shoemaker formation rocks, though without strong Zn and Ni enrichments. From its elevated $\mathrm{Ca}$ and $\mathrm{S}$, Deadwood also appears to contain a small amount ( $\sim 10 \%)$ of Homestake-like material. Typical Meridiani basaltic sand could comprise up to $30 \%$ of the total (MI images suggest $20-30 \%$ contamination), but not more because $\mathrm{Mn} / \mathrm{Fe}$ would become untenably low. We interpret Deadwood to be a clastic sedimentary rock dominated by grains from the Shoemaker formation, with minor $\mathrm{CaSO}_{4}$, perhaps as cement. Basaltic sand contaminates the APXS measurement, but does not change this interpretation.

The key stratigraphic and crosscutting relationships along the western margin of Cape York are depicted in Figure 6. We interpret the inner portion of the bench, characterized by Deadwood, to be the first sedimentary unit to form on Endeavour's rim, dominated by material shed from the Cape York breccias. This material, and the basal Burns formation sandstone that unconformably overlies it, were subsequently cut by fractures that were filled by gypsum precipitated from sulfate-rich fluids generated within the nearby Noachian crust. These fluids were likely at low temperature (if hydrothermal, they were distal), since anhydrite would be expected otherwise. In pure water the gypsum/anhydrite conversion temperature is $\sim 40-60^{\circ} \mathrm{C}$, and in concentrated brines it can be substantially lower (37). Calcium sulfate was precipitated closest to the Noachian source rocks, rather than other sulfates (e.g., $\mathrm{MgSO}_{4} \bullet n \mathrm{H}_{2} \mathrm{O}$; $\mathrm{FeSO}_{4} \bullet n \mathrm{H}_{2} \mathrm{O}$ ) or chlorides, because of its lower solubility. Some gypsum was also precipitated as cement in the bedrock. Unlike the Burns formation sulfates that dominate the Meridiani plains 
and are rich in jarosite $(2,3)$, the gypsum of Homestake does not require acidic fluids for its formation. We suggest, however, that the fluids from which the gypsum was precipitated may have been a contributor to the overall hydrologic budget responsible for formation of the Meridiani sulfate sandstones.

The absence of substantial deformation of the veins suggests there has been minimal transformation between gypsum and anhydrite since emplacement. The molar volumes of these minerals differ by a factor of $\sim 1.6$; in terrestrial settings, such transformations typically produce complex deformation features (38). The absence of gypsum-anhydrite transformations further suggests that these rocks remained at relatively low temperatures since vein emplacement.

Development of the materials investigated at Endeavour began with an impact into basaltic rocks, producing breccias with a stratigraphy similar to that observed at some comparably sized terrestrial impact craters. Degradation and shedding of these breccias formed thin sedimentary materials immediately surrounding Cape York, over which the basal Burns formation sandstones were unconformably deposited. Emplacement of the gypsum veins then took place, postdating the earliest Burns formation sandstones, but probably predating much of the rest of the Burns formation stratigraphy encountered by Opportunity.

The ubiquity of impact breccia at Cape York contrasts with the only other Noachian terrain explored in situ, the Columbia Hills in Gusev Crater. The Spirit rover encountered great lithologic diversity there, including materials interpreted as impact ejecta (11). However, none were breccias, and none had the lateral extent of the Shoemaker formation. We suggest that the difference can be attributed to Opportunity's sampling of the rim deposits of a single large crater, rather than Spirit's sampling of more distal ejecta from multiple impacts. 
The gypsum veins at Cape York provide clear evidence for relatively dilute (water activity $\left.\mathrm{a}_{\mathrm{w}} \sim 0.98(39)\right)$ water at moderate temperature, perhaps supporting locally and transiently habitable environments. More broadly, rocks at Cape York appear to record early events in a transition from (commonly) hydrothermal waters that altered basaltic crust to phyllosilicates (40) to sulfate-charged ground waters that generated salt-rich sandstones deposited widely over the Meridian plains and elsewhere.

\section{References and Notes}

1. The Noachian is a geologic system on Mars representing the oldest period of the planet's geologic history, characterized by high impact rates.

2. S.W. Squyres et al., J. Geophys. Res. 111, E12S12 (2006).

3. R.E. Arvidson et al., J. Geophys. Res. 116, E00F15 (2011).

4. J.J. Wray et al., Geophys. Res. Lett. 36, L21201 (2009).

5. A sol is defined as one martian solar day.

6. Shoemaker Ridge is named to honor the late Eugene M. Shoemaker, one of the founders of planetary geoscience.

7. Greeley Haven is named to honor the late Ronald Greeley, distinguished planetary scientist and member of the Athena Science Team.

8. S.W. Squyres et al., J. Geophys. Res. 108, 8062 (2003).

9. The Miniature Thermal Emission Spectrometer (Mini-TES) was not used for this investigation because of temperature-related instrument degradation and optically thick dust on its mirrors accumulated during a prior global dust storm. The Mössbauer Spectrometer was not used because of the decay of its ${ }^{57} \mathrm{Co}$ radiation source.

10. T. Myrick et al., in Proceedings of AIAA Space 2004 Conference and Exhibit, pp. 1-11 (2004).

11. S.W. Squyres et al., J. Geophys. Res. 111, E02S11 (2006).

12. R.E. Arvidson et al., Science 306, 1730 (2004).

13. D. Stöffler and R.A.F. Grieve, Ch. 2.11 in Fettes, D. and Desmons, J. (eds.) Metamorphic Rocks: A Classification and Glossary of Terms, Recommendations of the International Union of Geological Sciences, Cambridge University Press (2007).

14. C. Meyer et al., Geol. Soc. Am. Bull. 123, 2312 (2011).

15. M.E. Schmidt et al., J. Geophys. Res. 113, E06S12 (2008).

16. C.G. Wheat, R.A. Feely, and M.J. Motti, Geochim. Cosmochim. Acta 60, 3593 (1996).

17. Deevey, E.S., Sci. Am. 223, 149 (1970).

18. J. Pohl et al., in Impact and Explosion Cratering, Pergamon Press, pp. 343-404 (1977).

19. W.v. Engelhardt et al., Meteoritics 30, 279 (1995).

20. W.v. Engelhardt, Tectonophysics 171, 250 (1990).

21. F. Hörz, R. Ostertag, and D.A. Rainey, Rev. Geophys. 21, 1667 (1983). 
22. W.v. Engelhardt, Meteoritics \& Planetary Science 32, 545 (1997).

23. H.E. Newsom et al., J. Geophys. Res. 91, 239 (1986).

24. J.M. Franklin, J.W. Lydon, and DF. Sangster, Econ. Geol. $75^{\text {th }}$ Anniv. Vol., 485 (1981).

25. J.A. Rathbun and S.W. Squyres, Icarus 157, 362 (2002).

26. J. Zipfel et al., Met. Planet. Sci. 46, 1 (2011).

27. D.W. Mittlefehldt et al., Lunar Planet. Sci. 41, 2109 (2009).

28. A $4 \mu \mathrm{m}$ thick dust layer is the simplest model that fits the APXS data; the actual dust coating is probably discontinuous and variable in thickness.

29. A Wang et al., J. Geophys. Res.113, E12S40 (2008).

30. M.S. Rice et al., Icarus 205, 375 (2010).

31. S. Taber, J. Geol. 26, 56 (1918).

32. T.C. Gustavson et al., J. Sed. Res. A 64, 88 (1994).

33. M. El Tabakh et al., J. Sed. Res. 68, 88 (1998).

34. S.L. Philipp, Geol. Mag. 145, 831 (2008).

35. D.W. Durney and J.G. Ramsay, in K.A. de Jong and R. Scholten (eds.) Gravity and Tectonics, Wiley, pp. 67-96 (1973).

36. P.D. Bons and M. Montenari, J. Struct. Geo. 27, 231 (2005).

37. D. Freyer and W. Voigt, Monatsh. Chem. 134, 693 (2003).

38. W.M. Bundy, J. Sed. Res. 26, 240 (1956).

39. N.J. Tosca, A.H. Knoll, and S.M. McLennan, Science 320, 1204 (2008).

40. B.L. Ehlmann et al., Nature 479, 53 (2011).

41. J.F. Bell III et al., J. Geophys. Res. 108, 8063 (2003).

42. R.N. Clark et al., USGS Digital Spectral Library splib06a, U.S. Geological Survey, Digital Data Series, 231, http://http://speclab.cr.usgs.gov/spectral.lib06/ (2007).

43. M. Anand et al., Abstract \#2173, presented at the $39^{\text {th }}$ Lunar and Planetary Science Conference, League City, TX, 10 to 14 March 2008.

44. J.A. Barrat et al., Meteoritics Planet. Sci. 36, 23 (2001).

45. J.A. Barrat et al., Geochim. Cosmochim. Acta 66, 3505 (2002).

46. J.A. Barrat et al., Meteoritics Planet. Sci. 37, 487 (2002).

47. Basaltic Volcanism Study Project (1981). Pergamon Press, Inc., New York. A-11, 70.

48. M. Burger et al., Meteoritics 24, 256 (1989).

49. A. Burghele et al., Abstract \#1041, presented at the $14^{\text {th }}$ Lunar and Planetary Science Conference, Houston, TX, 14 to 18 March 1983.

50. G. Dreibus et al., Meteoritics 27, 216 (1992).

51. G. Dreibus et al., Meteoritics Planet. Sci. 31, A39 (1996).

52. G. Dreibus et al., Meteoritics Planet. Sci. 35, A49 (2000).

53. G. Dreibus et al., Meteoritics Planet. Sci. 37, A43 (2002).

54. G. Dreibus et al., NIPR International Symp. "Evolution of Solar System Materials", 19 (2003).

55. M.B. Duke, Shock Metamorphism of Natural Materials, Mono Book Corp., 613 (1968).

56. A.J. Easton, C. J. Elliott, Meteoritics 12, 409 (1977).

57. M. Ebihara et al., Antarctic Meteorite Res. 10, 83 (1997).

58. L. Folco et al., Meteoritics Planet. Sci. 35, 827 (2000).

59. P. Gillet et al. Meteoritics Planet. Sci. 40, 1175 (2005).

60. J. D. Gleason et al., Geochim. Cosmochim. Acta 61, 4007 (1997).

61. A. Greshake et al., Geochim. Cosmochim. Acta 68, 2359 (2004). 
62. J. Gross et al., Meteoritics Planet. Sci. 46, 116 (2011).

63. Y. Ikeda et al., Antarctic Meteorite Res. 19, 20 (2006).

64. A.J. Irving et al., Abstract \#1547, presented at the 41st Lunar and Planetary Science Conference, Woodlands, TX, 1 to 5 March 2010.

65. A. Jambon et al., Meteoritics Planet. Sci. 37, 1147 (2002).

66. E. Jarosewich, Meteoritics 25, 323 (1990).

67. D.Y. Jerome, Ph.D. Dissertation, U. of Oregon (1970).

68. P. Kong et al., Geochim. Cosmochim. Acta 63, 1865 (1999).

69. D.A. Kring et al., Meteoritics Planet. Sci. 38, 1833 (2003).

70. J.C. Laul (1987) Proc. Lunar Planet. Sci.Conf. 17th, E633 (1987).

71. J.C. Laul et al., Geochim. Cosmochim. Acta 50, 909 (1986).

72. Y. Lin et al., Meteoritics Planet. Sci. 43, 1179 (2008).

73. G.W. Lugmair and A. Shukolyukov, Geochim. Cosmochim. Acta 62, 2863 (1998).

74. M.-S. Ma et al., Proc. Lunar Planet. Sci.Conf. $12^{\text {th }}, 1349$ (1981).

75. T.S. McCarthy et al., Meteoritics 9, 215 (1974).

76. T.J. McCoy et al., Geochim. Cosmochim. Acta 56, 3571 (1992).

77. K. Misawa, Antarctic Meteorite Res. 17, 1 (2004).

78. D.W. Mittlefehldt et al., Antarctic Meteorite Res. 10, 109 (1997).

79. D.W. Mittlefehldt et al., Meteoritics Planet. Sci. 34, 357 (1999).

80. C.R. Neal et al., Abstract \#1671, presented at the 32nd Lunar and Planetary Science Conference, Houston, TX, 12 to 16 March 2001.

81. A.E. Rubin et al., Geology 28, 1011 (2000).

82. A.B. Sarbadhikari et al., Geochim. Cosmochim. Acta 73, 2190 (2009).

83. R.A. Schmitt et al., Meteoritics 7, 131 (1972).

84. N. Shirai and M. Ebihara, Antarctic Meteorite Res. 17, 55 (2004).

85. M.R. Smith et al., Proc. Lunar Planet. Sci. Conf. $14^{\text {th }}$, B612 (1984).

86. E. Stolper and H. Y. McSween, Geochim. Cosmochim. Acta 43, 1475 (1979).

87. L.A. Taylor et al., Meteoritics Planet. Sci. 37, 1107 (2002).

88. D. Terribilini et al., Meteoritics Planet. Sci. 33, 677 (1998).

89. A.H. Treiman et al., Meteoritics 29, 581 (1994).

90. H.C. Urey and H. Craig, Geochim. Cosmochim. Acta 4, 36 (1953).

91. H. Wänke et al., Abstract \#1468, presented at the $17^{\text {th }}$ Lunar and Planetary Science Conference, Houston, TX, 17 to 21 March 1986.

92. P.H. Warren and G.W. Kallemeyn, Abstract \#1539, presented at the $18^{\text {th }}$ Lunar and Planetary Science Conference, Houston, TX, 16 to 20 March 1987.

93. P.H. Warren and G.W. Kallemeyn, Meteoritics Planet. Sci. 31, 97 (1996).

94. P.H. Warren, and G.W. Kallemeyn, Antarctic Meteorite Res. 10, 61 (1997).

95. K. Yanai and H. Kojima, Catalog of Antarctic Meteorites, National Institute of Polar Research (Japan) (1995).

96. J. Zipfel et al., Meteoritics Planet. Sci. 35, 95 (2000).

This research was carried out for the Jet Propulsion Laboratory, California Institute of Technology, under a contract with NASA. 


\section{Figures:}

Fig. 1: Opportunity's traverse along the rim segment of Endeavour Crater named Cape York. Major features discussed in the text are indicated. Image acquired by the Mars Reconnaissance Orbiter HiRISE camera. North is at the top.

Fig. 2: Pancam false color mosaic of the rock Chester Lake acquired on Sol 2709 using the 753, 535, and $432 \mathrm{~nm}$ filters, sequence p2394. Scale across the image is about $1 \mathrm{~m}$. Square shows location of Microscopic Imager (MI) image (inset) acquired on Sol 2713. Scale across MI image is $\sim 3 \mathrm{~cm}$. Clasts in Chester Lake, which stand out in relief, are poorly sorted and irregularly shaped. The MI image shows irregular to cuspate fluting that is aligned with the orientations of elongate clasts.

Fig. 3: Ejecta blocks from Odyssey crater. Pancam false color image (a) of the block Tisdale acquired on Sol 2690 using the 753, 535, and $432 \mathrm{~nm}$ filters, sequence p2387. Height of Tisdale is about $30 \mathrm{~cm}$. Square shows location of MI image (b) acquired on Sol 2696. Scale across MI image is about $2.5 \mathrm{~cm}$. Pancam false color image (c) of the ejecta block Kidd Creek acquired on Sol 2694 using the 753, 535, and $432 \mathrm{~nm}$ filters, sequence p2593. Scale across Kidd Creek is about $1 \mathrm{~m}$. All images show a lithic breccia texture, with clasts ranging in size from tens of $\mathrm{cm}$ to near the resolution limit of MI images.

Fig. 4: Pancam approximate true color image (a) of the vein Homestake acquired on Sol 2769 using the 753, 535, and $432 \mathrm{~nm}$ filters, sequence p2574. Scale across the image is about $40 \mathrm{~cm}$. Inset shows location of MI mosaic (b) acquired on Sol 2766.

Fig. 5: Pancam "hydration signature" data (a) overlain on a $754 \mathrm{~nm}$ image of Homestake acquired on Sol 2769, sequence p2574. Colors indicate regions where the 934 to $1009 \mathrm{~nm}$ spectral slope is negative and where four other hydration signature spectral parameters (29) are also met. Comparison of Pancam relative reflectance $\left(\mathrm{R}^{*}(41)\right)$ spectra of Homestake to laboratory reflectance spectra (42) of three calcium sulfates with different levels of hydration (b). Solid lines are full-resolution lab spectra; points indicate lab spectra values convolved to Pancam bandpasses. The anhydrite, gypsum, and bassanite data are offset by $+0.2,0.0$, and -0.2 reflectance units, respectively. The inset shows the magnitude of the negative 934 to $1009 \mathrm{~nm}$ spectral slope values for these three mineral samples compared to the minimum, average, and maximum Pancam Homestake values. Error bars represent estimated 1-sigma uncertainties on the laboratory and Pancam ratio values. Logarithmic plot, units are $10^{-4} \mathrm{~nm}^{-1}$.

Fig. 6: Schematic east-west cross section, with large vertical exaggeration, through the western flank of Cape York. Materials shed from the Shoemaker formation breccias form the lowest sedimentary unit, which includes Deadwood. This unit is overlain by the sulfate-rich sandstones of the Burns formation; the heavy line separating them represents an unconformity. The Deadwood unit and the basal portion of the Burns formation closest to Cape York are cut by fractures; these fractures are filled with gypsum that was precipitated from waters arising from the underlying breccias. 


\section{Figures:}

Fig. 1: Opportunity's traverse along the rim segment of Endeavour Crater named Cape York. Major features discussed in the text are indicated. Image acquired by the Mars Reconnaissance Orbiter HiRISE camera. North is at the top.

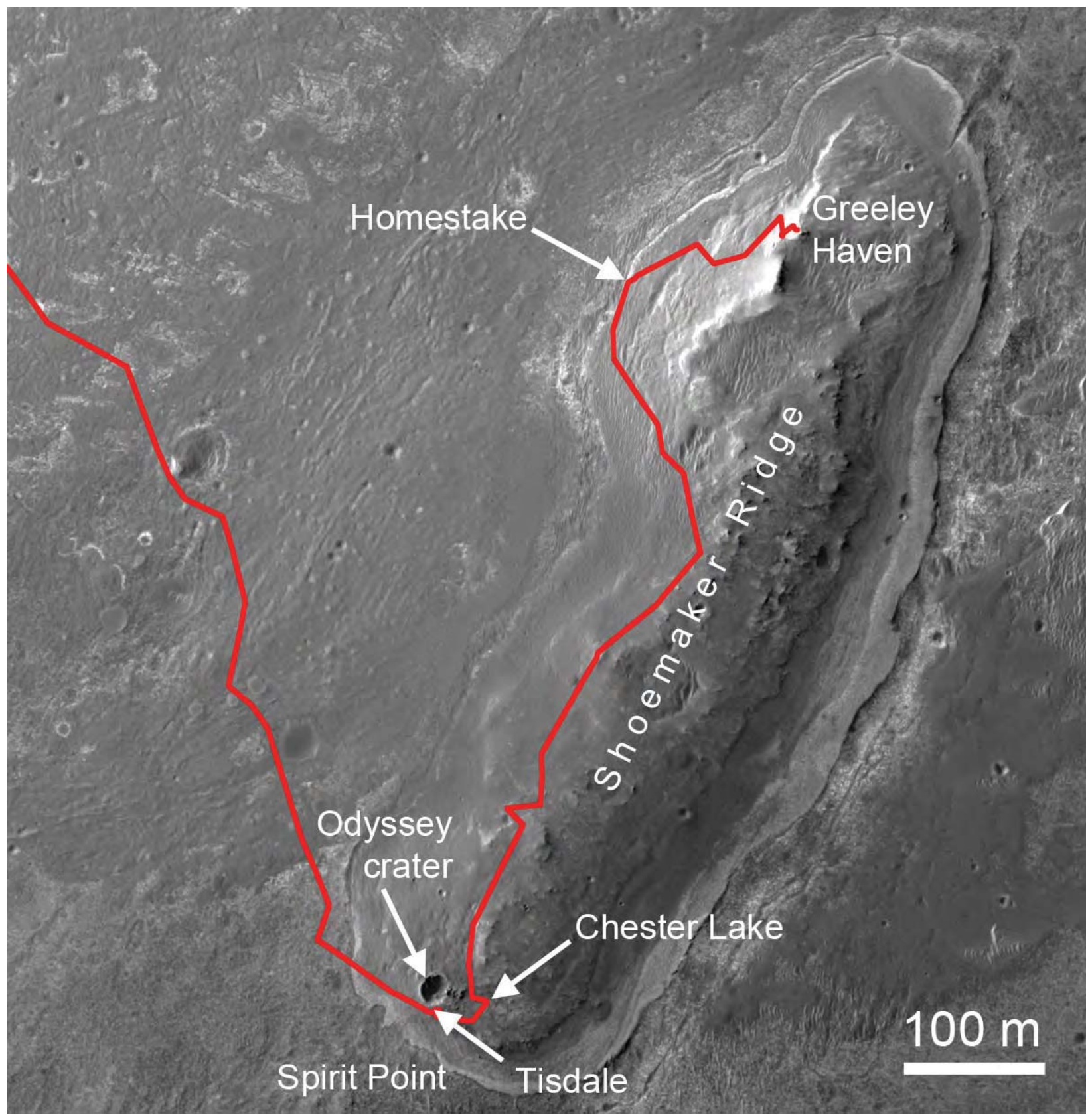


Fig. 2: Pancam false color mosaic of the rock Chester Lake acquired on Sol 2709 using the 753, 535 , and $432 \mathrm{~nm}$ filters, sequence p2394. Scale across the image is about $1 \mathrm{~m}$. Square shows location of Microscopic Imager (MI) image (inset) acquired on Sol 2713. Scale across MI image is $\sim 3 \mathrm{~cm}$. Clasts in Chester Lake, which stand out in relief, are poorly sorted and irregularly shaped. The MI image shows irregular to cuspate fluting that is aligned with the orientations of elongate clasts.

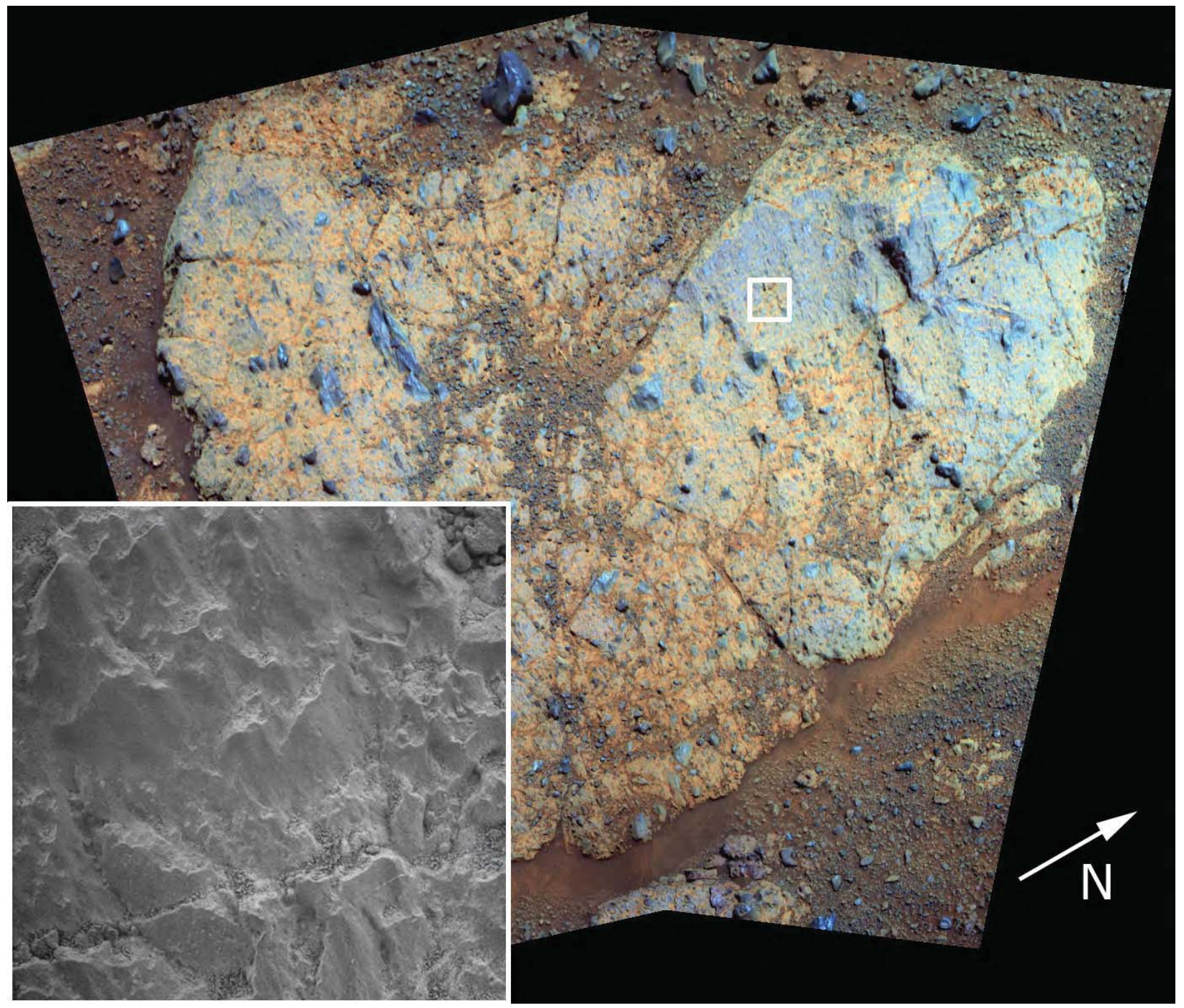


Fig. 3: Ejecta blocks from Odyssey crater. Pancam false color image (a) of the block Tisdale acquired on Sol 2690 using the 753, 535, and $432 \mathrm{~nm}$ filters, sequence p2387. Height of Tisdale is about $30 \mathrm{~cm}$. Square shows location of MI image (b) acquired on Sol 2696. Scale across MI image is about $2.5 \mathrm{~cm}$. Pancam false color image (c) of the ejecta block Kidd Creek acquired on Sol 2694 using the 753, 535, and $432 \mathrm{~nm}$ filters, sequence p2593. Scale across Kidd Creek is about $1 \mathrm{~m}$. All images show a lithic breccia texture, with clasts ranging in size from tens of $\mathrm{cm}$ to near the resolution limit of MI images.

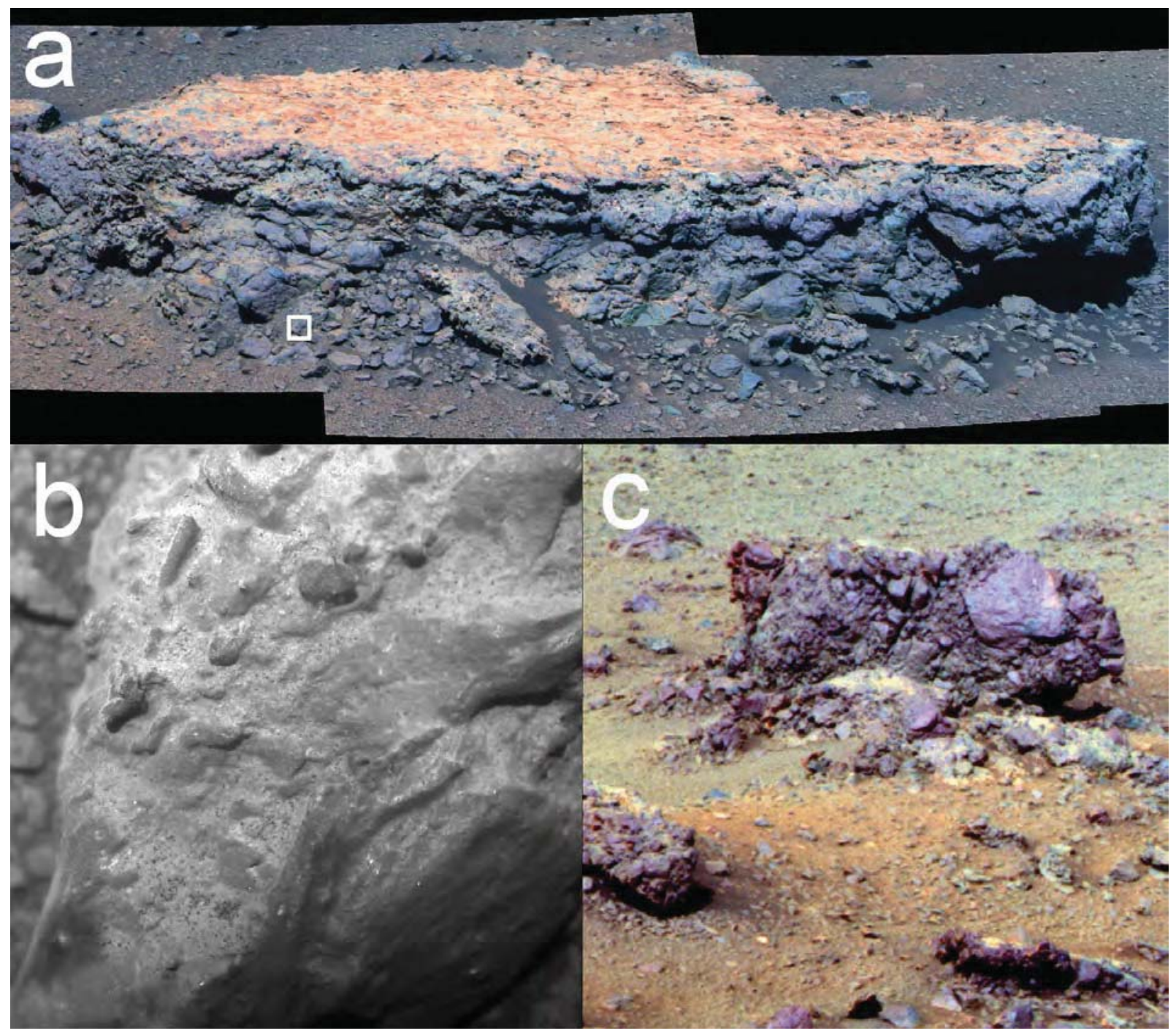


Fig. 4: Pancam approximate true color image (a) of the vein Homestake acquired on Sol 2769 using the 753, 535, and $432 \mathrm{~nm}$ filters, sequence p2574. Scale across the image is about $40 \mathrm{~cm}$. Inset shows location of MI mosaic (b) acquired on Sol 2766. Note the characteristic linear texture aligned perpendicular to the long axis of the vein.

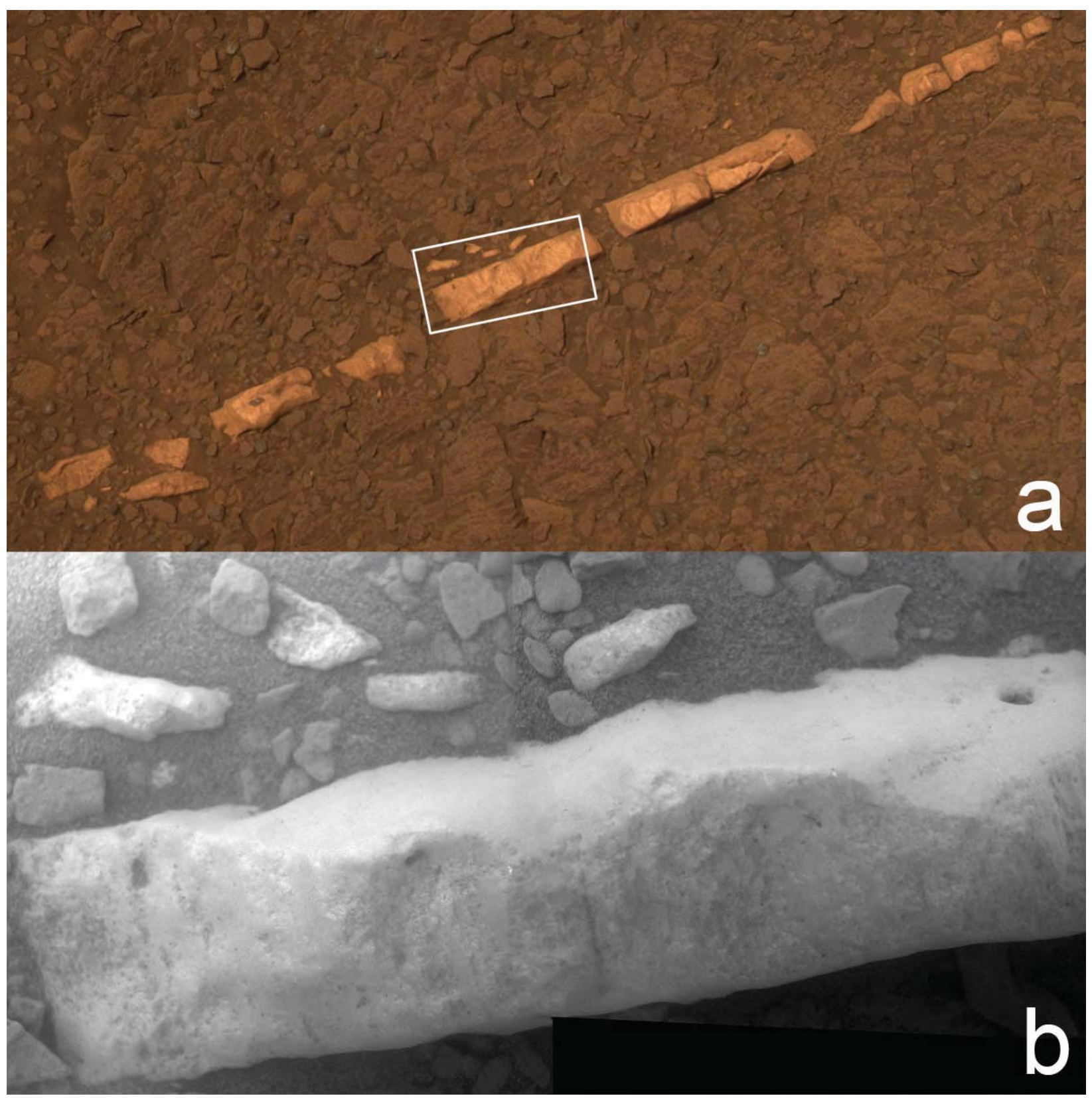




\section{Anhydrite}
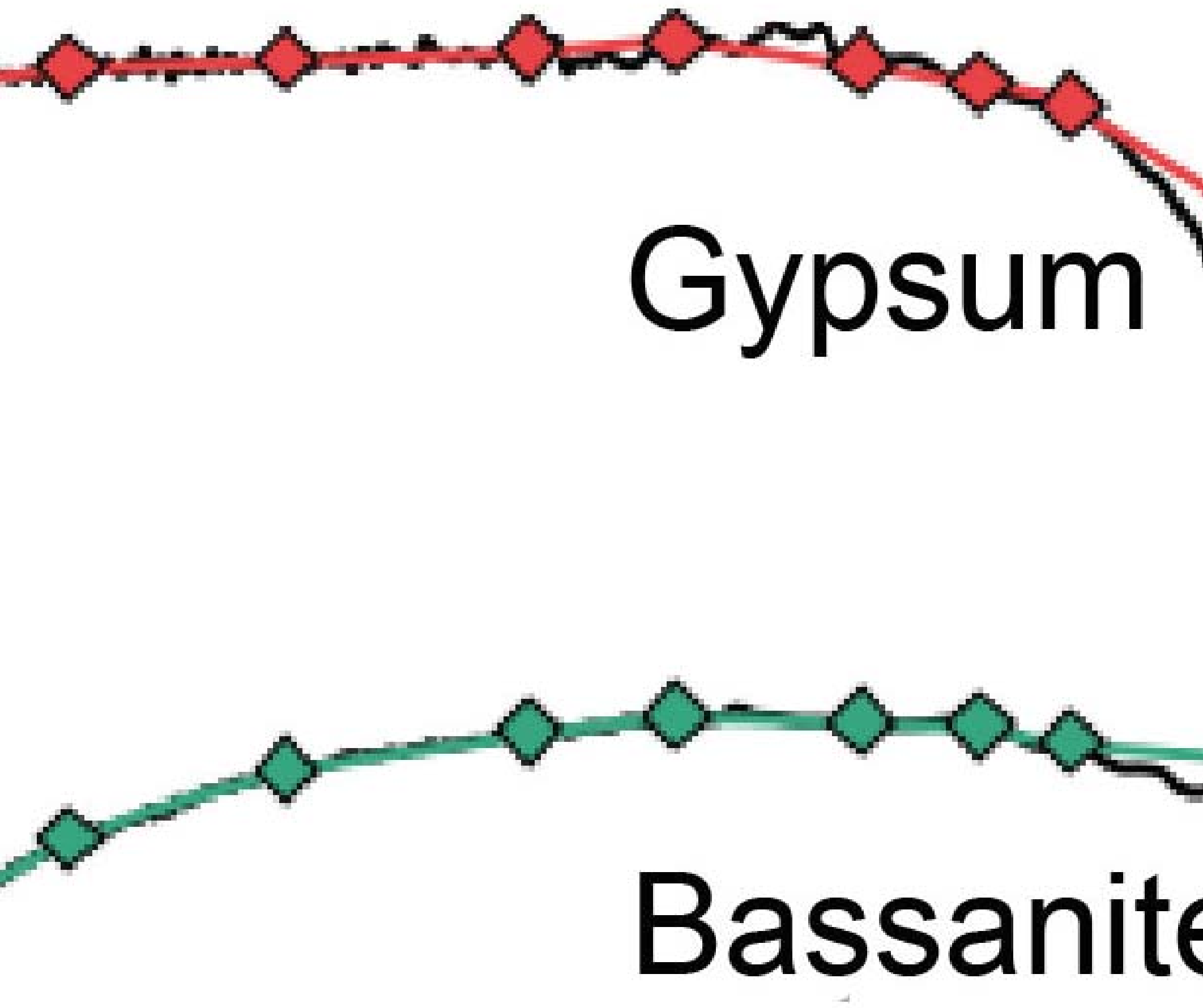


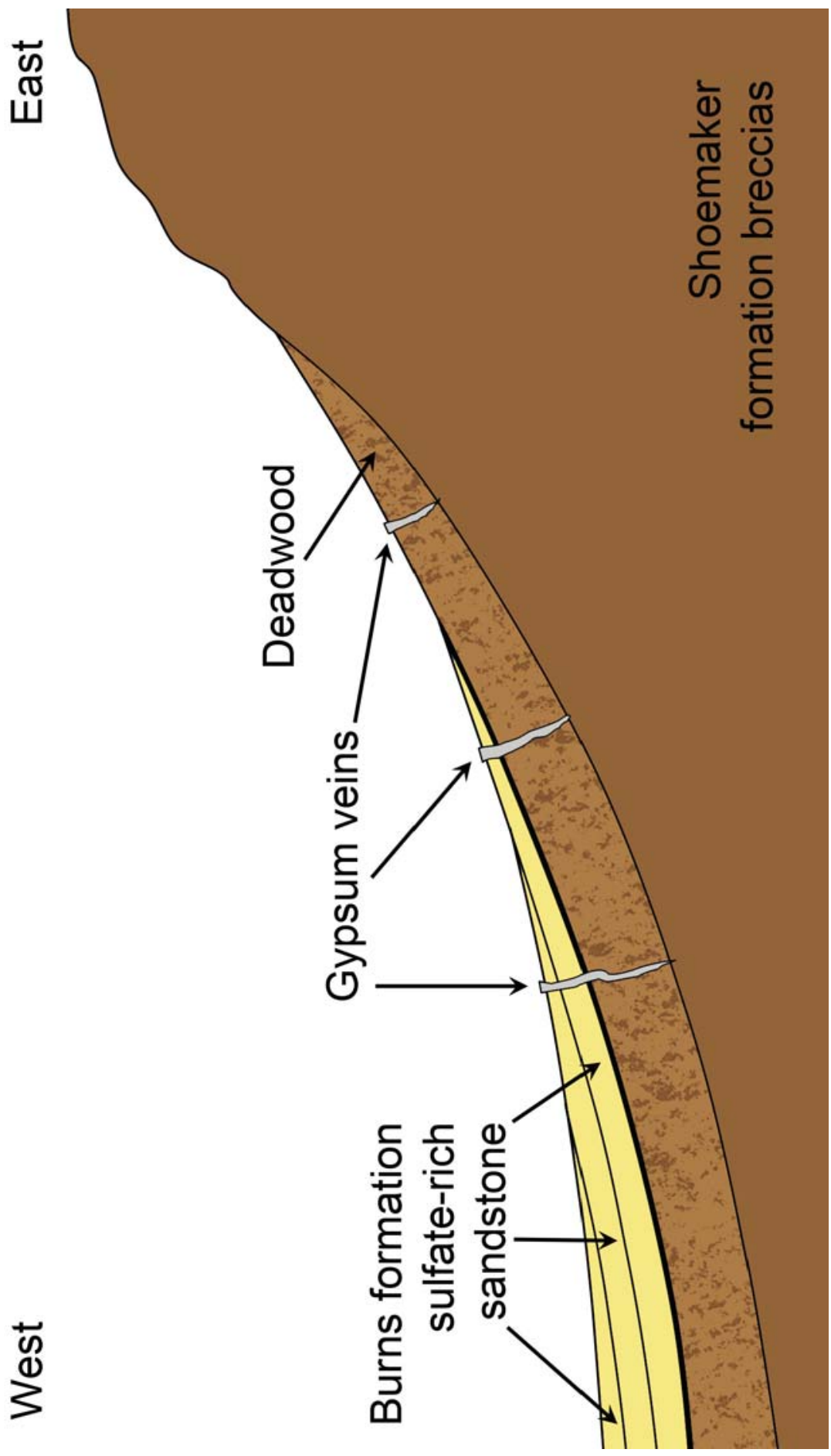


Fig. S1 (Supplemental online material): Compositional comparison of Cape York materials to martian basaltic/lherzolitic meteorites, and averages of Meridiani Planum basaltic sand, Burns formation, Adirondack Class basalt and Laguna Class soils (the latter two from Gusev crater). Martian meteorites demonstrate igneous fractionation trends (arrows) in $\mathrm{Cr}_{2} \mathrm{O}_{3}$ vs. "Mg number" (molar $100 \times \mathrm{Mg} /\left(\mathrm{Mg}+\mathrm{Fe}_{\mathrm{T}}{ }^{2+}\right)$ ) (a), $\mathrm{Cr}_{2} \mathrm{O}_{3}$ vs. $\mathrm{TiO}_{2}$ (b) and $\mathrm{P}_{2} \mathrm{O}_{5}$ vs. $\mathrm{TiO}_{2}$ (c). Shoemaker formation rocks are consistent with these trends.
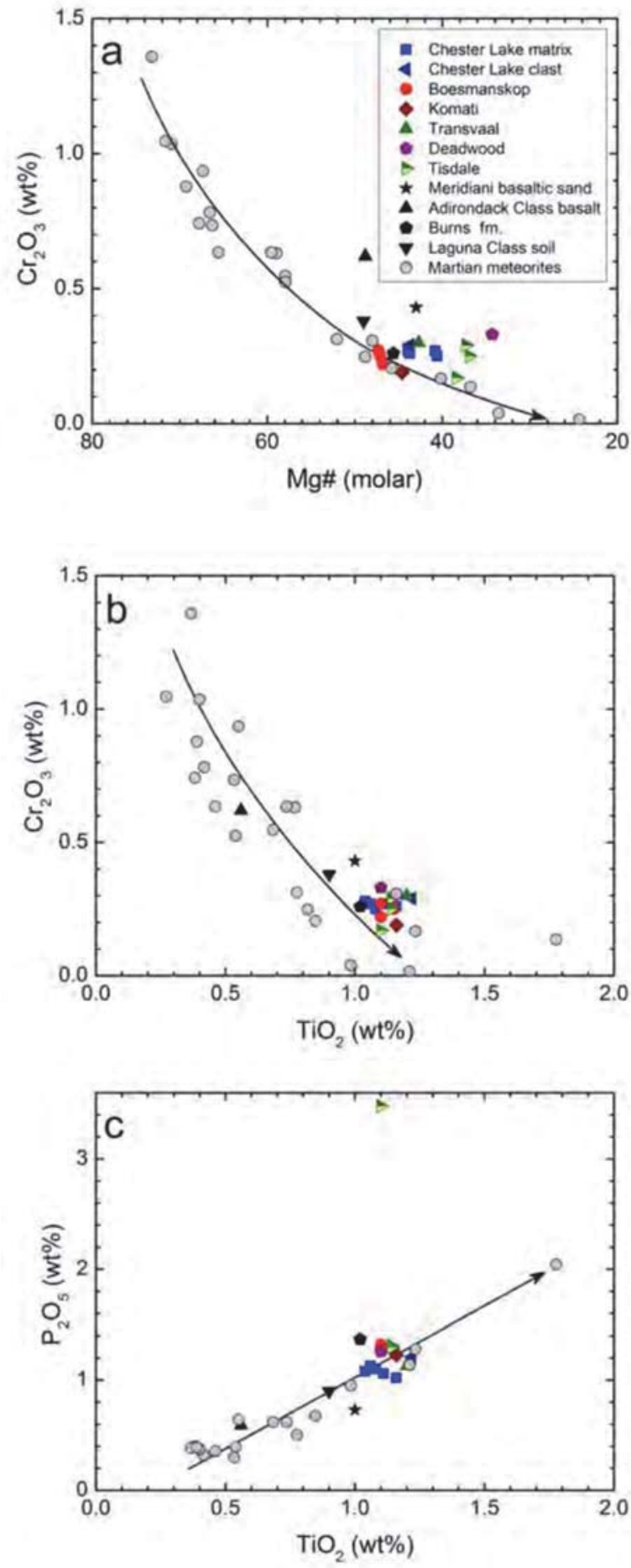
Fig. S2 (Supplemental online material): Elemental composition of Chester Lake and Greeley Haven targets (a) and Tisdale targets (b) calculated on a S- and Cl-free basis, and normalized to an average Burns formation composition. The gray boxes show $\pm 10 \mathrm{wt} \%$ deviations and the yellow boxes $\pm 20 \mathrm{wt} \%$ deviations from the normalizing composition. Inset in (b) shows the extreme ranges for $\mathrm{P}, \mathrm{Ni}$ and $\mathrm{Zn}$ in Tisdale targets.
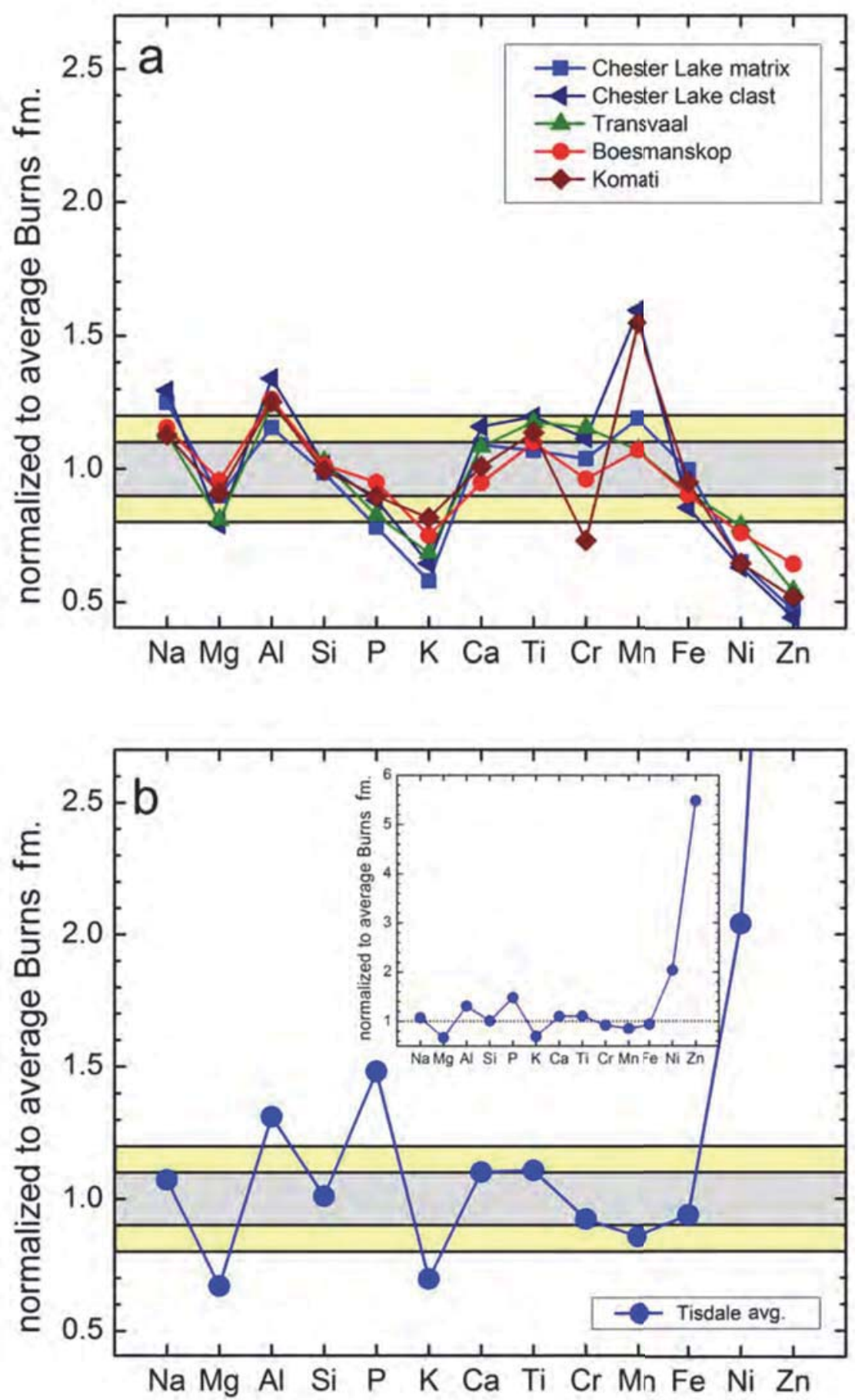
Supplemental Online Material: Literature sources for martian meteorite compositions used in Fig. S1:

Anand et al. (2008) Lunar Planet. Sci. XXXIX:2173

Barrat et al. (2001) Meteoritics Planet. Sci. 36:23

Barrat et al. (2002) Geochim. Cosmochim. Acta 66:3505

Barrat et al. (2002) Meteoritics Planet. Sci. 37:487

Basaltic Volcanism Study Project (1981) Pergamon Press, A-11:70

Burger et al. (1989) Meteoritics 24:256

Burghele et al. (1983) Lunar Planet. Sci. XIV:80

Dreibus et al. (1992) Meteoritics 27:216

Dreibus et al. (1996) Meteoritics Planet. Sci. 31:A39

Dreibus et al. (2000) Meteoritics Planet. Sci. 35:A49

Dreibus et al. (2002) Meteoritics Planet. Sci. 37:A43

Dreibus et al. (2003) NIPR International Symp. "Evolution of Solar System Materials",19

Duke (1968) Shock Metamorphism of Natural Materials, Mono Book Corp., 613

Easton \& Elliott (1977) Meteoritics 12:409

Ebihara et al. (1997) Antarctic Meteorite Res. 10:83

Folco et al. (2000) Meteoritics Planet. Sci. 35:827

Gillet et al. (2005) Meteoritics Planet. Sci. 40:1175

Gleason et al. (1997) Geochim. Cosmochim. Acta 61:4007

Greshake et al. (2004) Geochim. Cosmochim. Acta 68:2359

Gross et al. (2011) Meteoritics Planet. Sci. 46:116

Ikeda et al. (2006) Antarctic Meteorite Res. 19:20

Irving et al. (2010) Lunar Planet. Sci. 41:1547

Jambon et al. (2002) Meteoritics Planet. Sci. 37:1147

Jarosewich (1990) Meteoritics 25:323

Jerome (1970) Ph.D. Dissertation, U of Oregon

Kong et al. (1999) Geochim. Cosmochim. Acta 63:1865

Kring et al. (2003) Meteoritics Planet. Sci. 38:1833

Laul (1987) Proc. Lunar Planet. Sci.Conf. 17:E633

Laul et al. (1986) Geochim. Cosmochim. Acta 50:909

Lin et al (2008) Meteoritics Planet. Sci. 43:1179 
Lugmair \& Shukolyukov (1998) Geochim. Cosmochim. Acta 62:2863

Ma et al. (1981) Proc. Lunar Planet. Sci.Conf. 12:1349

McCarthy et al. (1974) Meteoritics 9:215

McCoy et al. (1992) Geochim. Cosmochim. Acta 56:3571

Misawa (2004) Antarctic Meteorite Res. 17:1

Mittlefehldt - unpublished

Mittlefehldt et al. (1997) Antarctic Meteorite Res. 10:109

Mittlefehldt et al. (1999) Meteoritics Planet. Sci. 34:357

Neal et al. (2001) Lunar Planet. Sci. XXXII:1671

Rubin et al. (2000) Geology 28:1011

Sarbadhikari et al. (2009) Geochim. Cosmochim. Acta 73:2190

Schmitt et al. (1972) Meteoritics 7:131

Shirai \& Ebihara (2004) Antarctic Meteorite Res. 17:55

Smith et al. (1984) Proc. Lunar Planet. Sci.C 14:B612

Stolper \& McSween (1979) Geochim. Cosmochim. Acta 43:1475

Taylor et al. (2002) Meteoritics Planet. Sci. 37:1107

Terribilini et al. (1998) Meteoritics Planet. Sci. 33:677

Treiman et al. (1994) Meteoritics 29:581

Urey \& Craig (1953) Geochim. Cosmochim. Acta 4:36

Wänke et al. (1986) Lunar Planet. Sci. XVII:919

Warren \& Kallemeyn (1987) Lunar Planet. Sci. XXVIII:1056

Warren \& Kallemeyn (1996) Meteoritics Planet. Sci. 31:97

Warren \& Kallemeyn (1997) Antarctic Meteorite Res. 10:61

Yanai \& Kojima (1995) Catalog of Antarctic Meteorites, National Institute of Polar Research (Japan)

Zipfel et al. (2000) Meteoritics Planet. Sci. 35:95 